\title{
A TESE DO MARCO TEMPORAL DA OCUPAÇÃO QUILOMBOLA À LUZ DA TEORIA DA INTEGRIDADE DE DWORKIN: ANÁLISE DOS VOTOS DA ADIN 3239
}

\author{
Aianny Naiara Gomes Monteiro* \\ Girolamo Domenico Treccani**
}

\section{RESUMO:}

Este trabalho analisa os votos dos ministros do STF na Ação Direta de Inconstitucionalidade (ADIN) n. 3239 acerca da tese do marco temporal quilombola, com a utilização de pesquisa bibliográfica e documental, dividindo-se em quatro partes: explanação do direito das comunidades quilombolas a partir da Constituição Federal de 1988; apresentação da ADIN n ${ }^{\circ}$ 3239 e da tese do marco temporal; procedida à análise dos votos que se manifestaram pela aplicação desta tese aos territórios quilombolas a partir teoria do direito como integridade de R. Dworkin, finalmente, é exposto como alguns outros ministros do STF apresentam sua posição sobre este tema.

Palavras-chave: Marco temporal; ADIN no 3239; comunidade de quilombo; integridade do direito; Dworkin.

\section{THE THESIS OF TEMPORAL FRAMEWORK IN QUILOMBOLA OCCUPATION UNDER DWORKIN'S THEORY OF INTEGRITY: ANALYSIS OF THE VOTES IN DAU N. 3239}

\begin{abstract}
:
This article analyzes the vote of the Supreme Court of Brazil in the judgment of Direct Action of Unconstitutionality n. 3239 regarding the thesis of the quilombola temporal framework, using of bibliographical and documentary research. It's dividing in four parts: explanation about the quilombolas communities rights from the Federal Constitution (1988); presentation of DAU n. 3239 and the thesis of the temporal framework; analysis of the minister's votes that manifested by the application of this thesis to the quilombolas territories from the theory of law as integrity by Dworkin; and how the divergent ministers presented their position on this topic.
\end{abstract}

Keywords: Temporal framework; DAU $n^{\circ} 3239$; community of quilombo; integrity of law; Dworkin.

\section{Introdução}

\footnotetext{
Doutoranda no Programa de Pós-Graduação em Direito, da Universidade Federal do Pará. Mestra em Agricultura Familiar e Desenvolvimento Sustentável pelo Programa de Pós-Graduação em Agriculturas Amazônicas, da Universidade Federal do Pará. Advogada. E-mail: aiannymonteiro@ yahoo.com.br.

** Doutor em Desenvolvimento Sustentável do Trópico Úmido pelo Núcleo de Altos Estudos Amazônicos da Universidade Federal do Pará. Mestre em Direito Agrário pela Universidade Federal do Pará. Professor dos Cursos de Pós-Graduação e Graduação em Direito da Universidade Federal do Pará. Advogado. E-mail: jeronimotreccani@gmail.com.
} 
Muitos juristas e antropólogos brasileiros consideram a Constituição Federal de 1988 um marco no reconhecimento de povos indígenas, comunidades quilombolas e demais comunidades tradicionais. No caso povos indígenas, por exemplo, temos uma significativa mudança paradigmática: se abandona a teoria da "integração" à sociedade nacional, como estava previsto nas normas anteriores, para se respeitar sua identidade cultural ${ }^{1}$. O art. 215 consagra os indígenas e os afro-brasileiros como construtores da identidade nacional dandolhe uma relevância antes desconhecida. Qualquer debate sobre territorialidade, portanto, a partir deste momento, deverá ser intrinsecamente relacionado com esta identidade cultural.

Finalmente, o Decreto $\mathrm{n}^{\circ}$ 6.040, de 7 de fevereiro de 2007, amplia os horizontes definindo a identidade e territorialidade das populações tradicionais, realçando de um lado a referência aos artigos 231 e 68 do Atos das Disposições Transitórias Constitucionais (ADTC) da Constituição Federal (CF/88) e do outro incorporando o princípio do auto reconhecimento previsto na Convenção 169 da Organização Internacional do Trabalho (OIT) ${ }^{2}$. A Ementa do

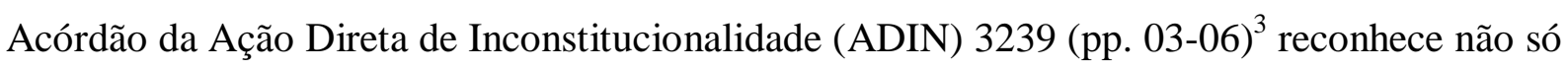
que esta Convenção se aplica às comunidades quilombolas, mas que é "Constitucionalmente legítima, a adoção da autoatribuição como critério de determinação da identidade quilombola" (BRASIL, 2019, p. 04) e acrescenta:

A Convenção 169 da Organização Internacional do Trabalho - OIT sobre Povos Indígenas e Tribais, consagra a "consciência da própria identidade" como critério para determinar os grupos tradicionais aos quais aplicável, enunciando que Estado algum tem o direito de negar a identidade de um povo que se reconheça como tal. (BRASIL, 2019, p. 04).

Em relação às comunidades quilombolas, de forma expressa, a Constituição, no artigo 68 dos ADCT, lhes reconheceu a propriedade definitiva a esses grupos. A redação deste importante artigo foi interpretada pelos Ministros do Supremo Tribunal Federal (STF), nos

\footnotetext{
${ }^{1}$ A partir de1934 as Constituições Federais passaram a defender os direitos indígenas, mas o Art. $5^{\circ}$ daquela $\mathrm{CF}$ apresentava a seguinte redação: "Compete privativamente à União: XIX - legislar sobre: m) incorporação dos silvícolas à comunhão nacional". A mesma norma (art. 129) defende a posse das terras onde mesmos se achem permanentemente localizados. As constituições de 1937 (art. 154); 1946 (art. 216); 1967 (art. 186); 1969 (art. 198) reiteram este direito territorial, mas sem alterar esta visão integracionista. Já o art. 231 da atual Carta Magna altera substancialmente esta visão reducionista: “Art. 231. São reconhecidos aos índios sua organização social, costumes, línguas, crenças e tradições, e os direitos originários sobre as terras que tradicionalmente ocupam" (grifo nosso).

$2 \mathrm{O}$ art. $1^{\circ}$ da Convenção 169 da OIT determina: Artigo $1^{\circ} 1$. A presente convenção aplica-se: a) aos povos tribais em países independentes, cujas condições sociais, culturais e econômicas os distingam de outros setores da coletividade nacional, e que estejam regidos, total ou parcialmente, por seus próprios costumes ou tradições ou por legislação especial; [...] 2. A consciência de sua identidade indígena ou tribal deverá ser considerada como critério fundamental para determinar os grupos aos que se aplicam as disposições da presente Convenção.

3 As referências à decisão feitas neste trabalho utilizarão os números das páginas do arquivo em pdf.
} 
autos da ADIN no 3239, sendo algumas destas interpretações no sentido de dar uma compreensão restritiva a extensão da expressão "que estejam ocupando suas terras", apontando para o sentido de adoção da tese do marco temporal da ocupação, que autorizaria a regularização das terras reivindicadas por comunidades quilombolas, desde que as mesmas comprovassem a ocupação na data da promulgação da Constituição de 1988 (05 de outubro) ${ }^{4}$.

Neste sentido, este trabalho tem como objetivo apresentar os argumentos elaborados pelos ministros do STF acerca da aplicação do marco temporal da ocupação aos territórios quilombolas. Analisa os votos dos ministros Cezar Peluso, Rosa Weber ${ }^{5}$ e Dias Tofolli com base na teoria do direito como integridade de Dworkin, que propõe uma interpretação construtiva do direito a partir de casos complexos e compreende que o intérprete e aplicador dos normas jurídicas devem fazê-lo considerando os princípios que regem o ordenamento jurídico onde a norma está inserida e as decisões anteriores para encontrar a melhor solução. A tese do marco temporal é explicitamente repudiada nos votos dos Ministros Luiz Edson Fachin, Luís Roberto Barroso e Ricardo Lewandosky.

Dessa forma este trabalho apresenta, inicialmente, uma breve explanação do direito das comunidades quilombolas a partir da Constituição Federal de 1988, dando ênfase aos direitos territoriais reconhecidos no art. 68 do ADCT. Em seguida é apresentada a ADIN no 3239, abordando de forma os argumentos dos autores da Ação, as manifestações dos ministros em seus respectivos votos e da tese do marco temporal, com objetivo de demonstrar como a tese foi inserida no ordenamento brasileiro. Depois de proceder a análise dos votos que se manifestaram pela aplicação da tese do marco temporal aos territórios quilombolas a partir teoria do direito como integridade de Dworkin, expõe-se o posicionamento de outros Ministros. Metodologicamente, realizou-se uma pesquisa bibliográfico e documental.

Como conclusão, tendo como base na teoria do direito como integridade de R. Dworkin, entende-se que a interpretação do art. 68 do ADCT, no sentido da aplicação da tese do marco temporal aos territórios quilombolas, apresentada por alguns ministros do STF nos

\footnotetext{
${ }^{4}$ Esta tese foi um dos conceitos que foram estabelecidos no Acórdão da Petição $n^{\circ} 3.388$-RR que visou impugnar o ato demarcatório da Terra Indígena Raposa Serra do Sol, determinada pela Portaria $n^{\circ}$. 5334/2005, do Ministério da Justiça, homologada por Decreto Presidencial de 15 de abril de 20005 que promoveu a referida demarcação.

${ }^{5}$ Todos os votos analisados neste trabalho serão consultados a partir do inteiro teor do Acórdão do julgamento da ADIN nº. 3239, publicado em 01/02/2019. Excepcionalmente, no caso do voto da Ministra Rosa Weber, para fins de comparação, também será utilizada a versão do voto-vista proferido por ocasião do julgamento ocorrido em 25/03/2015, o qual foi modificado na versão final do acórdão.
} 
autos da ADIN n 3239, não se coaduna com o espírito da Constituição Federal de 1988, sendo, portanto, inadequada ao ordenamento jurídico pátrio.

\section{Direito territorial de Comunidades quilombolas}

O artigo 215, $\S 1^{\circ}$, da Constituição Federal de 1988, estabeleceu como obrigação do Estado a garantia do exercício dos direitos culturais e a proteção às manifestações culturais populares, indígenas e afro-brasileiras. O Art. 216, por seu turno, elevou à condição de patrimônio cultural brasileiro os bens de natureza material e imaterial, individualmente ou em conjunto, a identidade, a ação, a memória dos diferentes grupos formadores da sociedade brasileira $^{6}$.

Associado a estes direitos, no caso das comunidades quilombolas houve o reconhecimento à propriedade das terras tradicionalmente ocupadas por meio do Art. 68 do ADCT, que dispõe que "aos remanescentes das comunidades dos quilombos ${ }^{7}$ que estejam ocupando suas terras é reconhecida a propriedade definitiva, devendo o Estado emitir-lhes os títulos respectivos" (BRASIL, 1988).

Segundo Boyer (2009, p. 139), "com o art. 68, o Estado rompe definitivamente com a estigmatização do quilombo, já que se compromete a conceder os direitos específicos diferenciados aos descendentes de escravos fugitivos, em particular sobre as suas terras". Para tanto, a interpretação deste artigo, de acordo com Treccani (2015), deve ser realizada em harmonia com as disposições dos arts. 215 e 216 da CF/1988, tendo em vista que, assim como outros países da América Latina ${ }^{8}$, existe um autoreconhecimento do Brasil como estado pluriétnico e multicultural ${ }^{9}$.

\footnotetext{
6 Incluindo-se as formas de expressão; os modos de criar, fazer e viver; as criações científicas, artísticas e tecnológicas; as obras, objetos, documentos, edificações e demais espaços destinados às manifestações artísticoculturais; os conjuntos urbanos e sítios de valor histórico, paisagístico, artístico, arqueológico, paleontológico, ecológico e científico (art. 216, CF/1988).

${ }^{7}$ Treccani (2006) explica que o termo "remanescente" é uma categoria jurídica e antropológica recente que impôs uma série de dificuldades de interpretação, uma vez que não era utilizada antes de 1988, seja pelas comunidades interessadas, seja pelos historiadores, antropólogos e demais cientistas sociais. Como consequência, as comunidades, que não compreendem seu conteúdo, não a utilizam, especialmente porque há uma conotação pejorativa por traz da palavra que apresenta uma noção residual e de reminiscências não bem identificadas. Almeida (2002), por sua vez, explica que o art. 68 do ADCT, por adotar a categoria "remanescentes das comunidades de quilombo" seria mais voltado para o passado e para o que teria "sobrevivido" sob essa designação formal, reforçando a ideia de residual do termo "remanescente". Por este motivo, embora o termo utilizado pela legislação seja "remanescentes das comunidades dos quilombos", evitaremos o uso da expressão, optando pelo uso de expressões como "comunidades quilombolas", "comunidades negras" ou "quilombolas", apenas.

${ }^{8} \mathrm{~A}$ falta de reconhecimento dos direitos culturais e territoriais dos afrodescendentes tem uma dimensão latinoamericana como se pode verificar nos dois textos a seguir. A Viceministra de Interculturalidade do Ministério da
} 
É importante ressaltar, contudo, que o art. 68 do ADCT também é objeto de críticas de juristas e antropólogos, em função da opção reducionista do texto constitucional que adotou a definição historiográfica de quilombo como lugar de escravo fugido, que necessita ser ressignificada ou ressemantizada no contexto de aplicação dos direitos destes grupos (CASTILHO, 2012; TRECCANI, 2006). Há quem o considere discriminatório por tentar "reparar apenas parcial e incidentalmente uma injustiça histórica e reconhecer de maneira restrita um direito social essencial", quando define legalmente a condição de quilombo dentro dessa perspectiva de "remanescente", "fugitivos" e "distantes" (ALMEIDA, 2002, p. 62).

Não obstante, o objetivo do art. 68 do ADCT é garantir aos quilombolas o direito ao território tradicionalmente ocupado, por isso, O’Dwyer (2002) explica que a leitura global do texto constitucional considera não apenas uma "identidade histórica", pois qualquer invocação do passado deve corresponder a uma forma atual de existência capaz de realizar-se a partir de outros sistemas, importando uma forma mais adequada de identificação desses grupos.

É nesse sentido, que a noção de terras tradicionalmente ocupadas, conceito jurídico previsto no art. $231^{10}$ da Constituição Federal, que inicialmente representava as terras utilizadas pelos povos indígenas, tem sido utilizada igualmente no reconhecimento de direitos constitucionais de ocupação territorial dos quilombolas" "11 (O’DWYER, 2012).

Cultura do Peru, Patricia Balbuena Palacio (2015. p. 9) reconhece que: "Existe uma invisibilização da população afroperuana que implica no não reconhecimento da importância desta no desenvolvimento da republica e cultura peruana" (tradução nossa). Já Mosquera (2007, p. 17) mostra como o racismo foi acompanhado da negação da condição humana dos negros: "Espanhóis, ingleses, portugueses, franceses e holandeses para justificar sua escravização lhes negaram sua condição humana ou humanidade, convertendo-os numa mercadoria chamada "peças da Índia" [...]. O racismo e a exclusão racial nasceram do exílio forçado de suas culturas ancestrais, da negação de seus nomes milenares e do não reconhecimento e desrespeito de sua dignidade humana" (tradução nossa).

${ }^{9}$ Débora Duprat (2007) depois de escrever que: "não se coloca mais em dúvida que o Estado nacional é pluriétnico e multicultural" (p. 9), afirma que: "A Constituição de 1988 [...] passa a falar não só em direitos coletivos, mas também em espaços de pertencimento, em territórios [...]" (p. 12). Isso leva a uma profunda mudança paradigmática na interpretação das normas, exigindo que assegurarem efetivamente aos membros destes povos o gozo dos direitos que lhes são reconhecidos.

10 "Art. 231. São reconhecidos aos índios sua organização social, costumes, línguas, crenças e tradições, e os direitos originários sobre as terras que tradicionalmente ocupam, competindo à União demarca-las, proteger e fazer respeitar todos os seus bens" (grifo nosso) (BRASIL, 2016).

${ }^{11}$ Em voto proferido na ADI n. 3239, o Ministro Dias Toffoli (pp. 145-179), apresentou entendimento divergente a esse respeito. Para ele, as terras indígenas e os territórios quilombolas não possuem o mesmo tratamento jurídico dispensado pela Constituição Federal de 1988, pois embora sejam referidas como "terras tradicionalmente ocupadas", apresentam um regramento diferenciado. A CF/88 teria dispensado maior proteção às terras indígenas, estabelecendo sua posse permanente; enquanto aos quilombolas foi concedida a propriedade definitiva das terras que estivessem ocupando, considerando um "equívoco equiparar a titulação das terras das comunidades quilombolas com os critérios de demarcação das terras tradicionalmente ocupadas pelos índios, as quais são e sempre foram públicas" (BRASIL, 2019, p. 167). 
Com o reconhecimento dado à propriedade quilombola pela CF de 1988, surgiu a necessidade de estabelecer regras para a identificação e demarcação dessas terras. Atualmente, o "procedimento para identificação, reconhecimento, delimitação, demarcação e titulação das terras ocupadas por remanescentes das comunidades dos quilombos de que trata o art. 68 do ADCT” está previsto no Decreto n 4.887, de 20 de novembro de 2003.

Além de estabelecer as fases, obrigações e prazos do procedimento, o Decreto $n^{\circ} 4.887$ traz uma definição de "remanescente de comunidades de quilombo" ressaltando, no artigo $2^{\circ}$ que se trata de "os grupos étnico-raciais, segundo critérios de auto-atribuição, com trajetória histórica própria, dotados de relações territoriais específicas, com presunção de ancestralidade negra relacionada com a resistência à opressão histórica sofrida" (BRASIL, 2003).

O referido Decreto determina ainda a titulação coletiva do território com o registro em nome da associação que representa a comunidade titulada (Art. 17, Decreto $n^{\circ}$ 4.887/2003), além de estabelecer "que a terra não pode ser vendida, doada, penhorada, arrendada ou adquirida por usucapião" (PRIOSTE, ALVES, CAMERINI, 2011, p. 300) e determinar a desapropriação de terceiros não quilombolas que possuam títulos sobrepostos ao território titulado (art. 13, do Decreto $\mathrm{n}^{\mathrm{o}} 4.887 / 2003$ ).

Anterior ao Decreto 4.887/2003, a norma que regulamentava o procedimento para identificação comunidade quilombolas e demarcação das terras por elas ocupadas era o Decreto $\mathrm{n}^{\mathrm{o}} 3.912$, de 10 de setembro de 2001. Neste Decreto, somente seria reconhecida a propriedade sobre as terras comprimissem dois requisitos: a) que fossem ocupadas por quilombos em 1888; e b) estavam ocupadas por remanescentes das comunidades dos quilombos em 5 de outubro de 1988, data da promulgação da atual Constituição federal (BRASIL, 2001). Logo, somente eram consideradas como quilombolas as áreas ocupadas por comunidades negras no período de 1888 e 1988 (Art. $1^{\text {º }}$, único, incisos I e II).

Como se vê, já existia formalmente a previsão de um marco temporal da ocupação quilombola preceituada no Decreto $\mathrm{n}^{\mathrm{o}} 3.912 / 2001$, expressamente revogado pelo Decreto $\mathrm{n}^{\circ}$ $4.887 / 2003$, que estabelece no $\S 3^{\circ}$, do art. $2^{\circ}$, que são consideradas "terras ocupadas por remanescentes das comunidades dos quilombos as utilizadas para a garantia de sua reprodução física, social, econômica e cultural" (BRASIL, 2003).

Portanto, “o Decreto 4.887/2003 apresenta um conceito que respeita a trajetória histórica das comunidades quilombolas fazendo referência a sua resistência à opressão sofrida" (TRECCANI, 2015, p. 69) e, além disso, está fundamentado na Convenção 169, da 
Organização das Nações Unidas $(\mathrm{OIT})^{12}$, que consagra a auto identificação e auto reconhecimento como critérios fundamentais para a identificação dos povos indígenas e quilombolas, ao preceituar que em seu artigo $1^{\circ}$ que "A consciência de sua identidade indígena ou tribal deverá ser tida como critério fundamental para determinar os grupos aos quais se aplicam as disposições desta Convenção" (OIT, 2011).

Existe, portanto, um conjunto normativo que deve ser lido conjuntamente e não pode ser dissociado de uma interpretação dos direitos constitucionais das comunidades quilombolas, sob pena de limitar o alcance da proteção constitucional dos territórios tradicionalmente ocupados por estas comunidades.

$\mathrm{O}$ resgate deste direito territorial é de fundamental importância para garantir a liberdade destas comunidades, pois, como afirmam Cavalcante e Estela (2018, p. 10) “O termo 'quilombo', símbolo de resistência de escravizados e libertos afrodescendentes contra o racismo e a escravidão, permaneceu ausente da base legal brasileira, silenciando as vozes e a história daqueles que nunca abdicaram de se reconhecer como sujeitos de direitos, sendo o mais básico deles a liberdade".

Dessa forma, a tutela dada aos direitos territoriais pelo art. 68 do ADCT a estes grupos não possui uma base lege ferenda, que significa dizer que não é metajurídica, mas deriva do conjunto da própria Constituição Federal ${ }^{13}$ (PRIOSTE, 2015, p. 25). É dentro dessa discussão que surgem os questionamentos sobre a constitucionalidade do Decreto $n^{\circ} 4.887 / 2003$ e a defesa da aplicação da tese do marco temporal à ocupação quilombola, conforme será apresentado a seguir.

\section{A ADIN 3239 e a tese do marco temporal}

\footnotetext{
${ }^{12}$ A Convenção ${ }^{\circ} 169$ da OIT, foi assinada em 1989 e ratificada pelo Brasil por meio do Decreto Legislativo ${ }^{\circ}$ 142 , de 19 de junho de 2002, através do Decreto Legislativo n. 142/2002, e promulgada por meio do Decreto ${ }^{\circ}$ 5.051, de 19 de abril de 2004.

${ }^{13} \mathrm{O}$ autor se refere ao posicionamento do ex-Ministro Carlos Velloso emitido no parecer acostado à manifestação do amicus curiae da Confederação Nacional da Indústria - CNI, nos autos da ADIn 3239, citado e corroborado no voto do também ex-Ministro Cezar Peluso (pp. 14-77), que figurava na posição de relator da referida Ação. Peluso, que se pronunciou pela inconstitucionalidade formal e material do Decreto 4.887, de 2003, considerou os conceitos apresentados pelos estudos antropológicos e sociais como metajurídicos, embora tenha reconhecido a relevância dos trabalhos apresentados citando o seguinte trecho do parecer de Velloso: "Muito se escreveu a respeito do tema. A maioria dos trabalhos, bons trabalhos, é necessário registrar, são, entretanto, trabalhos metajurídicos, escritos sob o ponto de vista étnico - alguns chegam a falar num ramo do Direito, o Direito Étnico - sócio-antropológico e político. São bons trabalhos, repete-se, que pugnam mais pelo ideal de proteção aos descendentes dos quilombolas, o que é elogiável. Por tal razão, são muito mais de lege ferenda do que de lege lata, refletidores, portanto, do que devia ser, tendo em consideração os conceitos metajurídicos em que se assentam, do que efetivamente é, tendo em linha de conta conceitos jurídicos" (BRASIL, 2019, 32).
} 
A ADIN n ${ }^{\circ} 3.239-9 / 600$ - DF foi ajuizada no STF em 2004 pelo Partido Frente Liberal (PLF), atual Democratas (DEM), questionando a constitucionalidade do Decreto $\mathrm{n}^{\circ}$ 4.887, de 20 de novembro de 2003, por supostos vícios formal e material, fundamentando-se em quatro pontos (BRASIL, 2004):

a) Uso indevido da via regulamentar, pois, segundo o autor da Ação, o conteúdo do decreto seria matéria reservada à lei por regulamentar direta e imediatamente preceito constitucional e não tratar apenas da organização interna da administração.

b) Suposta impossibilidade da desapropriação de terceiros não quilombolas que possuam títulos sobrepostos ao território titulado, prevista no art. 13 caput e $\S 2^{\circ}$ do Decreto Federal $n^{\circ} 4.887 / 2003$; uso de recursos públicos para pagamento de futuras indenizações, sob o argumento de que o papel do Estado se limita apenas a emitir títulos às comunidades que fixaram residência nas terras desde 05 de outubro de 1988 e de que a hipótese de desapropriação não teria base constitucional e infra legal.

c) O critério da auto atribuição estabelecido pelo Decreto $\mathrm{n}^{\circ} 4.887 / 2003$ no art. $2^{\circ}$, caput e $1^{\circ}$, seria uma "mera manifestação de vontade do interessado" que daria azo para que se reconhecesse o direito a mais pessoas que aquelas efetivamente beneficiadas pelo art. 68 do ADCT. Afirma que seria necessário comprovar a "remanescência" e não a "descendência" das comunidades de quilombo, o que reforça a ideia de que somente fazem jus ao direito aqueles que estivessem na posse das terras em que se localizavam os quilombos no período da promulgação da Constituição de 1988.

d) Amplitude e sujeição às indicações fornecidas pelos interessados na definição das terras a serem reconhecidas às comunidades quilombolas, caracterizadas no art. $2^{\circ}, \S \S$, $2^{\circ}$ e $3^{\circ}$ do Decreto $n^{\circ} 4.887 / 2003$ como aquelas essenciais para a reprodução física, social, econômica e cultural e das comunidades quilombolas.

Não apresentaremos, contudo, todos os argumentos expostos pelos ministros do STF em resposta às questões colocadas pelo partido autor na ADIN no 3239 acima elencadas, pois não cabe no escopo deste artigo. Deter-nos-emos a apresentar os argumentos utilizados para responder à seguinte questão, bem apontada pelo Ministro Dias Toffoli em seu voto (pp. 145179): "para ser reconhecido o direito de propriedade, em que momento a comunidade deveria "estar ocupando suas terras"”? (BRASIL, 2019, p. 149).

Embora o objeto da ADIN no 3239 seja a declaração da inconstitucionalidade do Decreto $n^{\circ} 4.887 / 2003$, em dois momentos já se suscitava a existência de um marco temporal 
para a regularização de comunidades quilombolas. O partido autor da Ação defende que o Estado só estaria obrigado a emitir títulos às comunidades que estavam na posse das terras no momento da promulgação da CF, ou seja, em 05 de outubro de 1988.

O STF foi instado, mesmo que indiretamente, a se manifestar e interpretar o art. 68 do ADCT que resguarda aos quilombolas o reconhecimento da propriedade definitiva, buscando definir o alcance da expressão "que estejam ocupando suas terras". Essa questão evidencia a tese denominada "marco temporal da ocupação", aventada pela primeira vez no judiciário brasileiro na ação que questionou junto ao STF a demarcação da Terra Indígena Raposa Serra do Sol, no Estado de Roraima, Petição $n^{\circ} 3.388 / R^{14}$. A demanda tinha por objeto a

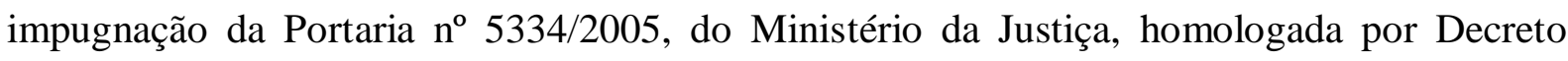
Presidencial de 15 de abril de 20005 que promoveu a referida demarcação.

$\mathrm{Na}$ decisão foram estabelecidos quatro "parâmetros" para o reconhecimento de terras indígenas, são eles: (i) o marco da tradicionalidade da ocupação; (ii) marco temporal da ocupação; (iii) o marco da concreta abrangência fundiária e da finalidade prática da ocupação tradicional; e, (iv) o marco do conceito fundiariamente extensivo do chamado "princípio da proporcionalidade. " (PEGORARI, 2017).

O marco temporal da ocupação de terras indígenas seria a data da promulgação da atual Constituição Federal Brasileira, ou seja, 05 de outubro de 1988, devendo os povos indígenas comprovar a efetiva posse nesta data, sem considerar outros fatores que tenham influenciado na saída dos povos indígenas de suas terras, tão pouco a greve limitação à realização da garantia ao direito ao território tradicionalmente ocupado reconhecido aos grupos indígenas do país:

Aqui, é preciso ver que a nossa Lei Maior trabalhou com data certa: a data da
promulgação dela própria (5 de outubro de 1988) como insubstitúvel referencial
para o reconhecimento, aos índios, 'dos direitos sobre as terras que tradicionalmente
ocupam'. Terras que tradicionalmente ocupam, atente-se, e não aquelas que
venham a ocupar. Tampouco as terras já ocupadas em outras épocas, mas sem
continuidade suficiente para alcançar o marco objetivo do dia 5 de outubro de
1988. (...). É exprimir: a data de verificação do fato em si da ocupação fundiária é o
dia 5 de outubro de 1988, e nenhum outro. (Grifo nosso) (BRASIL, 2009, p. 41).

Nessa senda, Pegorari (2017) apresenta severas críticas à decisão que estabelece de forma arbitrária a referida data, carregada de vicio da anti-historicidade, pois ignora o passado indigenista brasileiro e o caráter originário de seus direitos, assim como o histórico das graves violações dos direitos humanos desses povos por parte de particulares e do próprio Estado.

${ }^{14}$ http://portal.stf.jus.br/processos/detalhe.asp?incidente=2288693. 
O mesmo marco, por motivos jurídicos diversos, pretende-se aplicar à titulação das terras quilombolas. Nos autos da ADIN. $n^{\circ}$. 3239, a advocacia-Geral da União e a Procuradoria-Geral da República suscitaram preliminar de não conhecimento da ação, argumentando que o Decreto $n^{\circ} 4.887 / 2003$ não possui autonomia, haja vista que se destina a regulamentar leis infraconstitucionais, a saber o art. 14, inciso IV, “c”, da Lei no 9.649/98, e do art. $2^{\circ}$, inciso III, e parágrafo único, da Lei $n^{\circ} 7.668 / 98$, e não o art. 68 do ADCT da Constituição Federal de 1988. Além disso, defenderam a improcedência da ação.

O ex-Ministro Cezar Peluso, então relator da ADIN no 3239, em seu voto (pp.14-77) se manifestou pela procedência da Ação e pela inconstitucionalidade formal e material do Decreto $\mathrm{n}^{\mathrm{0}} 4.887 / 2003$, modulando os efeitos da decisão para declarar os títulos válidos emitidos desde 1988 até a presente data. O ministro tratou de forma muito tímida o marco temporal, admitindo que as terras a serem demarcadas são aquelas cuja posse é secular e que subsistiam nos locais tradicionalmente conhecidos como quilombos na data da promulgação da Constituição Federal, marco mais gravoso do que o defendido pelos Ministros Rosa Weber, em seu primeiro voto, proferido em 2015, e Dias Toffoli (pp. 145-179).

A Ministra Rosa Weber, por sua vez, julgou improcedente a ação, declarando a constitucionalidade do Decreto ${ }^{\circ}$ 4.887/2003. Inicialmente, na primeira versão do voto-vista, a Ministra, argumentou que a demonstração da efetiva posse em 05 de outubro de 1988 é requisito essencial para a aplicação do art. 68 do ADCT (BRASIL, 2015). Na segunda versão do voto, acostada ao Acórdão (pp. 87-138), Weber, limitou-se a rejeitar a serventia metodológica da data de 13 de maio de 1888 para a definição do status dos quilombos:

À falta de deliberação do Plenário quanto a eventual marco temporal, deixo de tecer
considerações, ainda que em obter dictum a respeito, anotando, contudo, que a data
de 13 de maio de 1888 não tem serventia metodológica à definição do status dos
quilombos. A uma porque o próprio conceito de remanescente de quilombo nos dias
atuais exige a reprodução contínua de uma comunidade que, originada na resistência
à escravidão, permaneceu coesa. A duas porque é impossível saber, hoje, em que
momento do passado histórico a Lei Áurea, embora assinada naquela data, se tornou
de conhecimento público em localidades remotas do território brasileiro, bem como
a disposição que tiveram as autoridades locais de lhe conferir eficácia. Enfim, a data
da abolição formal da escravidão não induz a que após 13 de maio de 1888 não
tenha persistido o perverso regime em tal ou qual localidade. No universo
hipotético-formal dos juristas é que a figura do quilombo perde o sentido existencial
de forma simultânea à abolição, o mesmo não ocorrendo necessariamente na vida.
Convergem nessa linha as análises de autorizados juristas e antropólogos (BRASIL,
2019, p. 44).

No voto do Ministro Dias Toffoli (pp. 145-179), a ação foi julgada parcialmente procedente, declarando a constitucionalidade do Decreto impugnado, conferindo interpretação 
conforme ao $\S 2^{\circ}$ do art. $2^{\circ}$ do Decreto $n^{\circ} 4.887 / 2003$ novembro de 2003, para esclarecer, que somente devem ser titularizadas as áreas que estavam ocupadas por remanescentes das comunidades dos quilombos, incluindo as áreas efetivamente utilizadas para a garantia de sua reprodução física, social, econômica e cultural, na data da promulgação da Constituição Federal de 1988, ressalvando a comprovação, por todos os meios de prova juridicamente admitidos, da suspensão ou perda da posse em decorrência de atos ilícitos praticados por terceiros. O Ministro Gilmar Mendes (pp. 266-269) acompanhou integralmente o voto do Ministro Dias Toffoli.

Como visto, seja no voto do ex-Ministro Cezar Peluso, que admitiu a possibilidade de os quilombolas terem que comprovar a posse centenária, ou nos votos dos demais Ministros que assinalam para a adoção do marco temporal da ocupação quilombola, há uma interpretação reducionista do art. 68 do ADCT, ignorando o fato "de que o Estado assumiu o compromisso de reconhecer direitos territoriais a quem sofreu, e ainda sofre, os efeitos da escravidão" (PRIOSTE, ALVES, CAMERINI, 2011, p. 310-311).

Nesse ponto, recorre-se à teoria do direito como integridade proposto por Ronald Dworkin que propõe uma teoria de intepretação construtiva dos direitos para casos complexos. Considerando o contexto da $\operatorname{ADIN~n} n^{\circ} 3239$, a referida teoria fornece instrumental adequado para a análise dos votos dos ministros do STF quanto à aplicação do marco temporal na titulação das terras quilombolas.

\section{Análise dos votos à luz da teoria da integridade de Dworkin}

Conforme foi assinalado na seção anterior, alguns ministros propugnam pela existência do marco temporal para titulação dos territórios quilombolas, cuja data seria o dia 05 de outubro de 1988, quando foi promulgada a Constituição Federal.

O ex-Ministro Cezar Peluso (pp.14-77), designou os destinatários do art. 68 do ADCT, como "aqueles que subsistiam nos locais tradicionalmente conhecidos como quilombos, entendidos estes na acepção histórica, em 05 de outubro de 1988”' (grifo nosso) (BRASIL, 2019, p. 51). Para Peluso, a caracterização da posse seria reconhecida mediante a comprovação: a) do caráter contínuo e prolongado da posse (estejam ocupando); b) ser centenária (que remanescem); c) exercida com ânimo de dono (suas terras); d) e qualificada (existente em 05 de outubro de 1988) (BRASIL, 2019, p. 54). 
A Ministra Rosa Weber (pp. 87-138), por seu turno, descaracterizou a necessidade de comprovação de posse centenária, assim como o Ministro Dias Toffoli (pp. 145-179), em seus respectivos votos. Entretanto, ambos compreendem que o marco temporal é um requisito objetivo fundamental à proteção do art. 68 do ADCT.

Para Rosa Weber, a ocupação tem que ser continuada em 05 de outubro de 1988:

[...] a reprodução da unidade social que se afirma originada de um quilombo há de estar atrelada a uma ocupação continuada do espaço ainda existente, em sua organicidade, em 05 de outubro de 1988, de modo a se caracterizar como efetiva atualização histórica das comunidades dos quilombos. (BRASIL, 2015, p 40).

Para o Ministro Dias Toffoli (pp. 145-179), o art. 68 do ADCT alcança as áreas ocupadas por quilombolas que estavam ocupando as terras no momento da promulgação da Constituição Federal de 1988, legitimando uma situação fática presente, ou seja, as ocupações efetivas à época da promulgação do texto constitucional, excluindo as ocupações passadas e as futuras. Ou seja, estariam excluídas desta proteção, as comunidades já desintegradas no momento da promulgação da Carta de 1988, bem como daquelas comunidades que passaram a se auto identificar como remanescentes de quilombos após 05 de outubro de 1988; ou que somente após essa data vieram a ocupar terras tidas como reminiscências dos antigos quilombos. O Ministro acrescentou em seu voto, a necessidade da comprovação da suspensão ou perda da posse em decorrência de atos ilícitos praticados por terceiros.

Argumento interessante é trazido pelo Ministro Dias Toffoli (pp. 145-179) em seu voto para justificar a adoção do marco temporal da ocupação quilombola, segundo a qual não seria razoável interpretar o texto constitucional de forma a ampliar "em demasia" o comando do Art. 68 do ADCT, referindo-se ao fato de que a falta de delimitação de um marco incluiria entre as terras de propriedade comunidades dos quilombolas áreas que não eram por eles ocupadas à época da entrada em vigor da Constituição de 1988. Assim se manifesta o eminente Ministro:

Deixar em aberto a possibilidade de definição desse território a partir de parâmetros de "necessidade" ou mesmo de sua ampliação futura, sem critérios objetivos, é conferir insegurança jurídica a relações já essencialmente conflituosas, enfraquecendo, desse modo, a estabilidade jurídica que se quis alcançar com o reconhecimento expresso do território dessas comunidades (BRASIL, 2019, p. 170).

Este entendimento, contudo, reflete o posicionamento que limita o alcance do artigo 68 do ADCT, dissonando de outras decisões já tomadas pelo egrégio Tribunal com 
interpretações ampliativas dos direitos e garantias judiciais ${ }^{15}$ (MAUÉS, 2015). Considerando, portanto, o contexto e os argumentos apresentados para justificar a inserção do marco temporal com critério objetivo para a titulação de territórios quilombolas, o método hermenêutico proposto por Dworkin, possibilita a análise dos argumentos dos Ministros favoráveis à adoção do Marco Temporal nos autos da ADIN no 3239.

O método do direito como integridade propõe uma teoria de intepretação construtiva dos direitos para casos complexos. Esta teoria busca auxiliar os juízes a encontrarem respostas corretas para os casos analisados, levando com consideração a justiça, a equidade e o devido processo legal, como princípios orientadores (DWORKIN, 1999).

Dworkin $(1999,273)$ afirma que o direito como integridade "é tanto produto de interpretação abrangente da prática jurídica como quanto sua fonte de inspiração". Trata-se de um desdobramento do método Hércules que atribui à linguagem jurídica argumentos de princípios ou de políticas capazes de fornecer a melhor justificação da linguagem:

[...] uma vez que Hércules será levado a aceitar a tese dos direitos, sua interpretação das decisões judiciais será diferente de sua interpretação das leis em um aspecto importante. Quando interpreta as leis, ele atribui à linguagem jurídica, como vimos, argumentos de princípio ou de política que fornecem a melhor justificação dessa linguagem à luz das responsabilidades do poder legislativo. Sua argumentação continua sendo um argumento de princípio. Ele usa a política para determinar que direitos já foram criados pelo Legislativo. Mas, quando interpreta as decisões judiciais, atribuirá à linguagem relevante apenas argumentos de princípio, pois a tese dos direitos sustenta que somente tais argumentos correspondem à responsabilidade do tribunal em que foram promulgadas (DWORKIN, 2002, p.173).

Diferentemente do convencionalismo ${ }^{16}$ ou do pragmatismo ${ }^{17}$, teorias criticadas por Dworkin, a teoria do direito como integridade considera que o juiz deve ponderar as decisões

\footnotetext{
${ }^{15}$ Dentre as decisões, Maués (2015) cita o julgamento da Ação Popular n. 307, na qual o STF decidiu que "escritórios profissionais" também estão protegidos pela inviolabilidade prevista no art. $5^{\circ}$, XI, da $\mathrm{CF} / 88$, ampliando as hipóteses expressamente previstas na Constituição que se refere somente à casa como objeto da proteção constitucional. E as decisões proferidas no RE 325.822 e RE 578.562 que estendeu a imunidade tributária aos "lotes vagos e prédios comerciais em locação" e "cemitérios", respectivamente, quando sejam de propriedade de instituições religiosas, sendo que o art. 150, VI, b da Constituição de 1988 se refira somente a "templos de qualquer culto". O autor argumenta que estas decisões de interpretações ampliativas em matéria de direitos fundamentais respaldam a interpretação ampliativa do STF na ADIn 4.277 que reconheceu a união estável homoafetiva, tomando como base a teoria do direito como integridade de Dworkin.

${ }^{16}$ De acordo com Dworkin (1999), os convencionalistas consideram que as decisões políticas do passado podem influenciar decisões jurídicas, uma vez que a prática jurídica bem compreendida respeita as convenções e considera as suas conclusões, e nada mais, como direito. Portanto, as decisões políticas do passado se justificam pela coerção e não por apreciações de moralidade política. Em suas palavras, a concepção convencionalista proíbe a reivindicação de qualquer direito fora da convenção.

${ }^{17}$ Dworkin (1999) apresenta uma descrição do pragmatismo e, em linhas gerais, explica que os pragmáticos negam que as decisões políticas do passado, por si sós, tenham o condão de oferecer qualquer justificativa para o uso ou não do poder coercitivo do Estado. Suas justificativas seriam encontradas na justiça, na eficiência ou em alguma outra virtude contemporânea da própria decisão coercitiva. Dessa forma, encontram sua justificação em
} 
do passado, compreendendo o presente, para que possa interferir no futuro, com base em princípios convincentes, sem os quais não possuiria uma justificação. O autor assim caracteriza o direito como integridade:

O direito como integridade, portanto, começa no presente e só se volta para o passado na medida em que seu enfoque contemporâneo assim o determine. Não pretende recuperar, mesmo para o direito atual, os ideais ou objetivos práticos dos políticos que primeiro o criaram. Pretende, sim, justificar o que eles fizeram (às vezes incluindo, como veremos, o que disseram) em uma história geral digna de ser contada aqui, uma história que traz consigo uma afirmação complexa: a de que a prática atual pode ser organizada e justificada por princípios suficiente atraentes para um futuro honrado (DWORKIN, 1999, p. 274).

Dworkin usa a ideia de romance, dotado de continuidade e coerência. Esta obra, no caso a decisão judicial, seria escrito por diferentes autores como se fossem apenas um, para demonstrar que se deve interpretar o Direito de forma coerente com os mesmos princípios de justificação. Dessa forma, para Dworkin, o juiz é obrigado a invocar princípios para justificar sua decisão, levando em consideração tanto fontes sociais como fontes morais da natureza argumentativa (MACEDO JR., 2013).

Isso significa que a história política de uma comunidade é uma história melhor, se ela exibe os juízes mostrando claramente para o seu público, através de seus votos, o caminho que juízes posteriores guiados pela integridade vão seguir e se ele mostra juízes tomando decisões que confere tanto voz como efeito às convicções sobre a moralidade que são disseminadas pela comunidade (MACEDO JR, 2016, p. 89-90).

Logo, as decisões judiciais devem considerar as decisões políticas tomadas até então, os princípios e a moralidade que regem aquela comunidade. Dessa forma, acredita Dworkin, estaremos diante de boas decisões para casos difíceis. Diante disso, e tomando por base a teoria acima apresentada, a questão que se coloca é: qual é a melhor interpretação do Art. 68 dos ADCT da Constituição Federal de 1988?

Maués (2015), ao examinar a decisão do STF sobre união homoafetiva, explicou, utilizando os ensinos de Dworkin sobre a teoria do direito como integridade, que a chave "para formular os princípios morais e políticos que permitem reconstruir o conjunto das decisões constitucionais como um sistema coerente" (MAUÉS, 2015, p. 144), é a leitura cuidadosa do texto constitucional.

Portando, a resposta para compreender a expressão "que estejam ocupando", do art. 68 do ADCT, deve ser "buscada na interpretação dos princípios que buscam as decisões tomadas pelo constituinte sobre o tema" (MAUÉS, 2015, p. 144). Além disso, deve-se considerar o

decisões judiciais presentes, sendo que as decisões judiciais e legislativas anteriores não contribuem, em princípio, para a justiça ou a virtude de qualquer decisão atual. 
conjunto das decisões tomadas entre 1988 e o momento da manifestação do STF sobre o caso (MAUÉS, 2015). Nesse sentido, é importante apontar que no Brasil existe um conjunto normativo nos âmbitos federal, estadual e municipal, elaborados por estes entes no sentido de dar efetividade ao art. 68 do ADCT.

Além disso, o Brasil se tornou signatário de declarações, pactos e convenções internacionais que destacam o sentido político, histórico e social do reconhecimento à terra aos quilombolas. Assim para compreender se a decisão de aplicar o marco temporal à ocupação quilombola está de acordo com a integridade do direito proposta por Dworkin, deve-se levar em consideração todo este arcabouço.

\section{Os votos contrários à adoção do marco temporal}

Os votos dos Ministros Luiz Edson Fachin, Luís Roberto Barroso e Ricardo Lewandosky discordaram do posicionamento relativo ao "marco temporal" apresentado pelos colegas que os antecederam. Luiz Edson Fachin cita vários autores que comprovam a “invisibilidade jurídica” das comunidades quilombolas antes de 1988 e defende que:

Assim, dentro de uma hermenêutica constitucionalmente adequada à interpretação e aplicação de um direito fundamental que surge, pela vez primeira, na Constituição de 1988, não depreendo da redação do artigo 68 do ADCT a restrição do direito à titulação de propriedade apenas àqueles remanescentes de comunidades quilombolas que estivessem na posse mansa e pacífica da área na data da promulgação do texto constitucional (grifo nosso) (BRASIL, 2019, p. 213).

Fachin reforça sua posição manifestando a necessidade de garantir a máxima eficácia das normas constitucionais sob pena, no caso dos quilombos, não lhe reconhecer um direito fundamental fechando-lhe mais uma vez a porta:

Ademais, em consonância com o entendimento acima manifestado, entendo que, por
se tratar de direito fundamental, a interpretação adequada à sua aplicação deve levar
em consideração o princípio da máxima eficácia das normas constitucionais [...]
Entender-se que a Constituição solidificou a questão ao eleger um marco temporal
objetivo para a atribuição do direito fundamental a esse grupo étnico significa, com
todo o respeito aos posicionamentos em sentido contrário, fechar-lhes uma vez mais
a porta para o exercício completo e digno de todos os direitos inerentes à
cidadania. (grifo nosso) (BRASIL, 2019, p. 215).

Também o Ministro Luís Roberto Barroso se alinha ao posicionamento do Ministro

Fachin contrário ao marco temporal apresentando um conjunto diferenciado de possibilidades:

Presidente, concluindo, penso que meu voto está totalmente alinhado com a manifestação do Ministro Luiz Edson Fachin [...]. Fazem jus ao direito previsto no art. 68 do ADCT: 1. As comunidades que ocupavam suas áreas quando da promulgação da Constituição; e ainda 2. aquelas que foram delas desapossadas à força e cujo comportamento, à luz da sua cultura, indica intenção de retomar a permanência do vínculo cultural e tradicional com o território, dispensada a 
comprovação de conflito possessório atual de fato ou mediante ajuizamento de ação. (grifo nosso) (BRASIL, 2019, p. 222)

Outra voz que se associa na recusa de se estabelecer um marco temporal é a do Ministro Luiz Fux (pp. 284-322):

\begin{abstract}
Em verdade, a teleologia constitucional que informa o comando do art. 68 do ADCT desautoriza qualquer restrição cronológica de seu alcance. $\mathrm{O}$ eventual estabelecimento de um marco temporal, uma data certa que se valha de insubstituível referencial para a ocupação de um determinado espaço geográfico por uma comunidade, não se coaduna com a literalidade, nem com a teleologia da proteção constitucional assegurada aos remanescentes das comunidades quilombolas. É que a interpretação gramatical do texto constitucional não encontra qualquer referência em datas ou outro parâmetro temporal; ao contrário, vê "reconhecida" a propriedade definitiva. O dispositivo declara - e não constitui - o direito de propriedade, sem delimitar marcos temporais (grifo nosso) (BRASIL, 2019, p. 312).
\end{abstract}

O Ministro Ricardo Lewandowski (pp. 252-265) em seu voto não se manifesta expressamente sobre a questão do "marco temporal", mas recusa terminantemente que os quilombolas tenham que fazer a prova de que ocupavam um determinado lugar:

Os remanescentes dos quilombolas são descendentes daqueles que estão fugindo há mais de quinhentos anos. Como é que se vai fazer uma prova de fatos que ocorreram há quase meio século atrás? Evidentemente, essa prova é impossível. Não se pode admitir aqui, num grupo claramente hipossuficiente, que assuma o ônus da prova, que se inverta o ônus da prova (BRASI, 2019, p. 264).

Depois desta rápida apresentação dos diferentes votos, acredita-se que seja importante destacar ainda que um dos objetivos da Constituição Federal de 1988 é a construção de uma sociedade justa, livre e solidária (art. $3^{\circ}, \mathrm{I}, \mathrm{CF} / 88$ ) e a erradicação da pobreza e a marginalização, bem como a redução das desigualdades sociais e regionais (art. $3^{\circ}$, II, CF/88).

Ademais, o art. 68 do ADCT possui um caráter de reparação histórica, com o objetivo de, nas palavras do relator durante Assembleia Nacional Constituinte de 1987, "legitimar uma situação de fato e de direito, isto é, a posse e o domínio das comunidades negras sobre as áreas nas quais vivem" (TRECCANI, 2006, p. 83). O Art. 68, do ADCT, guarda, portanto, intrínseca relação com os direitos à vida, liberdade e igualdade, tidos como elementares do princípio da dignidade da pessoa humana, expresso no artigo $1^{\circ}$, III, da CF88.

Já foi assinalado na primeira seção deste artigo que o direito reconhecido no art. 68 do ADCT não é um dispositivo isolado e deve ser interpretado em harmonia com os arts. 215 e 216 associado ainda à leitura do Convênio 169 da OIT, que expressa no artigo 14.1 que se deve reconhecer aos povos interessados os direitos de propriedade e de posse sobre as terras que tradicionalmente ocupam (TRECCANI, 2006). A aplicação desta Convenção é expressamente prevista no Decreto $\mathrm{n}^{\circ} 5.051$, de 19 de abril de 2004. 
Deve-se considerar ainda que o Brasil aderiu à jurisdição da Corte Interamericana de Direitos Humanos (CorteIDH) por meio da ratificação da Convenção Interamericana de Direitos Humanos (CADH). Dessa forma, também são aplicados ao Brasil os ditames do Sistema Interamericano de Direitos Humanos (SIDH).

As decisões da Corte cada vez mais sinalizam para o reconhecimento integral dos direitos territoriais de povos indígenas e tribais, onde se enquadram as comunidades quilombolas $^{18}$. De acordo com Maués apud Moreira (2017), o STF adota os Tratados de Direitos Humanos como parâmetros de interpretação constitucional, sendo uma obrigação não apenas do judiciário, mas também do legislativo e do executivo utilizá-los.

Não se pode olvidar que esse arcabouço normativo representa a intenção política e moral do Estado de reconhecer juridicamente os direitos territoriais dos grupos escravizados durante o período imperial, mas também das comunidades negras que nos dias atuais ainda sofrem com os efeitos danosos de anos de escravidão, associado com os 100 anos de ausência de políticas efetivas de reparação desses danos, que compreende o momento da abolição da escravidão que se deu em 1888 até a promulgação da Constituição Federal de 1988.

Neste sentido se expressa Laranjera (2018, p. 279) “O território quilombola é situado como condição identitária da comunidade quilombola, pelo seu espaço-tempo de (in) formação da memória coletiva dos remanescentes de quilombos", qualquer restrição temporal resultaria na negação desta identidade. Por isso, o STF não pode, portanto, se afastar desses princípios para definir o alcance do art. 68 do ADCT, sob pena de se afastar do romance em cadeia mesmo que tenha decisões difíceis a tomar, conforme nos propõe Dworkin:

\begin{abstract}
Um romancista em cadeia tem, portanto, muitas decisões difíceis a tomar, e pode-se esperar que diferentes romancistas em cadeia tomem decisões diferentes. Mas suas decisões não incluem (nem estão devidamente resumidas como) a decisão de se deve ou não considerar um eventual afastamento do romance-em-execução que the foi entregue, e até que ponto fazê-lo. Afinal, ele não tem nada de que possa afastarse (ou a que se apegar) enquanto não elaborar um romance-em-execução a partir do texto. (grifo nosso) (DWORKIN, 1999, p. 285).
\end{abstract}

Dessa forma, podemos concluir que a decisão manifesta nos votos dos Ministros favoráveis à adoção do marco temporal na ADIN no 3239 não está de acordo com as exigências do direito como integridade, "que impõe ao Estado respeitar os princípios do

\footnotetext{
${ }^{18}$ Dentre os diversos casos apresentados pela CorteIDH, destaca-se o caso do Povo Saramaka vs. Suriname (2007), no qual a Corte unificou a jurisprudência sobre direitos de povos tribais e direitos indígenas, ao reconhecer ao Povo Saramaka, povo tribal que se assemelha às comunidades quilombolas do Brasil cujas raízes históricas se remetem à época da escravidão, que apesar de não ser indígena, possui características sociais, culturais e econômicas similares (MOREIRA, 2017).
} 
ordenamento jurídico em todos os seus atos” (MAUÉS, 2015, p. 157), posto que a limitação temporal aludida à 05 de outubro de 1988, esvazia o sentido de reparação histórica da política quilombola e desconsidera o conjunto normativo apresentado.

Neste momento de revisão dos conceitos históricos se faz necessário reafirmar que a escravidão não foi um mero "acessório" do sistema colonial e imperial do Brasil, mas que tinha "seus alicerces em um ordenamento jurídico que permitia que milhões de homens e mulheres fossem privados dos seus mais básicos direitos: a própria vida, bem como a sua dignidade e liberdade" (CAMPELLO, 2018, p. 17).

Silva e Marés de Souza Filho (2016, p. 69) também afirmam categoricamente que "a Constituição de 1988 não faz menção ao critério do marco temporal, sendo este uma invenção jurídica que vem sendo consolidada na intepretação do STF". Por isso é de fundamental importância resgatar o sentido correto do direito reconhecido pelo artigo 68 do ADCT: uma verdadeira "carta de alforria" concedida no século XX e consolidada com a decisão do STF no século XXI.

\section{Considerações Finais}

O contexto de aprovação do Art. 68 do ADCT da Constituição Federal de 1988 reconheceu o direito à propriedade definitiva de "remanescentes de comunidades de quilombo". Este dispositivo foi fruto de mobilização de movimentos negros que objetivavam do Estado políticas de reparação pelas violações a que foram submetidos seus antepassados e que até os dias atuais sofrem com o racismo institucional e a limitação do acesso à terra.

Buscou-se demonstrar, a partir da leitura dos votos dos ministros do Supremo Tribunal Federal na Ação Direta de Inconstitucionalidade no 3239 que a adoção da tese do marco temporal da ocupação aos territórios quilombolas contraria os princípios do ordenamento jurídico brasileiro, uma vez que impõe clara limitação ao alcance da expressão do texto do art. 68 do ADCT "que estejam ocupando", violando os preceitos que regem o reconhecimento dos direitos territoriais das comunidades quilombolas no Brasil. Essa compreensão, a partir da teoria de R. Dworkin, do direito como integridade, nos permite a firmar que a interpretação reducionista do art. 68 do ADCT adotada por alguns Ministros do STF nos autos da ADIN n ${ }^{\circ}$. 3239, não se coaduna com o espírito da Constituição Federal de 1988, portanto, é inadequada diante da complexidade social, histórica e jurídica que envolve as comunidades quilombolas. 
Destaca-se que é fundamental este reconhecimento para preservar as vidas destas comunidades, pois como afirmam Terra de Direitos e a CONAQ (2018, p. 132) "Titular territórios quilombolas no Brasil é combater o racismo, viabilizando a povos e comunidades negras condições materiais de desenvolver, com autonomia suas próprias formas de visa". A democracia brasileira precisa resgatar sua dívida histórica com os afro-brasileiros.

\section{REFERÊNCIAS BIBLIOGRÁFICAS}

ALMEIDA, Alfredo Wagner Berno de. Os Quilombolas e as novas etnias. In: O'DWYER, Eliane Cantarino (org.). Quilombos - Identidade étnica e territorialidade. Rio de Janeiro: Editora FGV e ABA, 2002, p. 43 - 81.

BOYER, Véronique. A construção do objeto quilombo. Da categoria colonial ao conceito antropológico. In: Antropolítica. Niterói, n. 27, 2009, p. 131-153.

BRASIL. Constituição da República Federativa do Brasil de 1988. Brasília-DF, fevereiro 2016. Disponível em: http://www.planalto.gov.br/ccivil_03/constituicao/constituicao.htm. Acesso em 11 de janeiro de 2018.

Ato das Disposições Transitórias. Brasília-DF, outubro, 1988. Disponível em: http://www.planalto.gov.br/ccivil_03/constituicao/constituicao.htm\#adct. Acesso em 11 de janeiro de 2018.

DECRETO N. 3.192, DE 10 DE SETEMBRO DE 2001. Regulamenta as disposições relativas ao processo administrativo para identificação dos remanescentes das comunidades dos quilombos e para o reconhecimento, a delimitação, a demarcação, a titulação e o registro imobiliário das terras por eles ocupadas. Brasília, setembro, 2001. Disponível em: http://www.planalto.gov.br/ccivil_03/decreto/2001/D3912.htm. Acesso em 11 de janeiro de 2018.

DECRETO No. 4.887, DE 20 DE NOVEMBRO DE 2003. Regulamenta o procedimento para identificação, reconhecimento, delimitação, demarcação e titulação das terras ocupadas por remanescentes das comunidades dos quilombos de que trata o art. 68 do Ato das Disposições Constitucionais Transitórias. Brasília, nov, 2003. Disponível em: http://www.planalto.gov.br/ccivil_03/decreto/2003/D4887.htm. Acesso em 11 de janeiro de 2018.

DECRETO No 5.051, DE 19 DE ABRIL DE 2004. Promulga a Convenção no 169 da Organização Internacional do Trabalho - OIT sobre Povos Indígenas e Tribais. Brasília, abril de 2004. Disponível em: http://www.planalto.gov.br/ccivil_03/_ato20042006/2004/decreto/d5051.htm Acesso em 11 de janeiro de 2019.

DECRETO No. 6.040, DE 7 DE 7 DE FEVEREIRO DE 2007. Institui a Política Nacional de Desenvolvimento Sustentável dos Povos e Comunidades Tradicionais. Brasília. fevereiro de 2007. Disponível em http://www.planalto.gov.br/ccivil_03/_Ato20072010/2007/Decreto/D6040.htm. Acesso em 11 de janeiro de 2019. 
. SUPREMO TRIBUNAL FEDERAL. ADI 3239-DF. Brasília. 2004. Disponível em http://portal.stf.jus.br/processos/downloadPeca.asp?id=15339396721\&ext=.pdf Acesso em 10 de março de 2019.

Disponível

SUPREMO TRIBUNAL FEDERAL. Acórdão ADI n . 3239-DF. Brasília. 2019.

http://portal.stf.jus.br/processos/downloadPeca.asp?id=15339396721\&ext=.pdff Acesso em 10 de março de 2019.

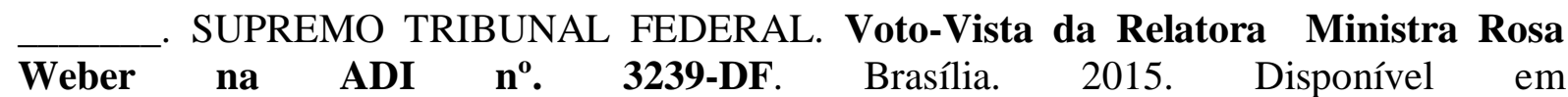
http://www.stf.jus.br/arquivo/cms/noticiaNoticiaStf/anexo/ADI3239RW.pdf. Acesso em 10 de janeiro de 2018.

SUPREMO TRIBUNAL FEDERAL. Voto do Relator Ministro Ayres Brito na

Pet. 3.338-RR. $\quad$ Brasília. $2009 . \quad$ Disponível http://redir.stf.jus.br/paginadorpub/paginador.jsp?docTP=AC\&docID=630133. Acesso em 10 de janeiro de 2018.

CAMPELLO, André Barreto. Manual Jurídico da Escravidão. Império do Brasil. Jundiaí (SP): Paço Editorial. 2018

CASTILHO, Ela Wiecko V. de. Introdução. In: LIMA, Antonio Carlos de Souza (Org.). Antropologia e Direito: temas antropológicos para estudos jurídicos (35-54). Brasília: Editora ContraCapa, 2012, p. 319 - 335.

CAVALCANTE, Raphael e ESTÊLA, Clarissa (Org.) Repertório bibliográfico sobre a condição do negro no Brasil. Brasília: Câmara dos Deputados. 2018.

DWORKIN, Ronald. O Império do Direito. $1^{a}$ edição. Tradução: Jefferson Luiz Camargo. São Paulo: Martins Fontes, 1999.

DUPRAT, Débora. O Direito sobre o marco da plurietnicidade /multiculturalidade. In DUPRAT, Débora (org). Pareceres Jurídicos: Direito dos povos e comunidades tradicionais. Manaus: UEA. 2007. pp. 9-19.

LARANJEIRA, Raymundo. O Negro e a Terra no Brasil. São Paulo: LTr. 2018.

MACEDO JR, Ronaldo Porto. A integridade no Direito e os protocolos de Hércules: comentários à integridade no Direito (Império do Direito - Capítulo VII). Revista Direito Mackenzie, v. 10, n. 2, 2016.

2013.

. Do xadrez à cortesia: Dworkin e a teoria do direito contemporânea, Saraiva, 
MAUÉS, Antonio Moreira. Capítulos de uma História: a decisão do STF sobre união homoafetiva à luz do direito como integridade. Revista Sequência, Florianópolis-SC, n. 70, jun. 2015, p. 135-162.

MOREIRA, Eliane Cristina Pinto. Justiça Socioambiental e Direitos Humanos. Uma análise a partir dos Direitos Territoriais de Povos e Comunidades Tradicionais. Rio de Janeiro: Lumen Juris, 2017.

MOSQUERA, Juan de Dios. La Población Afrocolombiana. Realidad, Derechos y Organización. Bogotá: Sigma Editores Ltda. 2007

O'DWYER, Eliane Cantarino. Introdução. In: O'DWYER, Eliane Cantarino (org.). Quilombos - Identidade étnica e territorialidade. Rio de Janeiro: Editora FGV e ABA, 2002, p. $13-41$.

- "Nation Building" e relações com o Estado: o campo de uma antropologia em ação. In: ZHOURI, Andréa (UFMG-ABA). (Org.). Desenvolvimento, reconhecimento de direitos e conflitos territoriais. 1ed. Brasília - DF: ABA Publicações, 2012, v., p. 236-254.

PALACIO, Patricia Balbuena, Apresentação, in BARRANTES, Maribel Arrelucea. AGUILAR, Jesús A. Cosamalón. La presencia afrodescendiente em el Perú. Siglos XVIXX, Lima, Ministério da Cultura, 2015.

PEGORARI, Bruno. A tese do "marco temporal da ocupação" como interpretação restritiva do direito à terra dos povos indígenas no Brasil: um olhar sob a perspectiva da Corte Interamericana de Direitos Humanos. ARAC $\hat{\mathbf{E}}$ - Direitos Humanos em Revista, Ano 4,| Número 5, Fevereiro 2017, p. 242 - 262.

PRIOSTE, Fernando. G. V.. Quilombos no Supremo Tribunal Federal: Decreto 4887/03 e a Efetividade da Constituição. In: PRIOSTE, Fernando Gallardo Vieira; ARAÚJO, Eduardo Fernandes. (Org.). Direito Constitucional Quilombola: Análises sobre a ação direta de inconstitucionalidade 3239. 1ed.Rio de Janeiro: Lumen Juris, 2015, v. 1, p. 21-58.

PRIOSTE, Fernando G. V.; ALVES, Coralina Caraíba N.; CAMERINI, João Carlos Bermeguy. Quem tem medo da Constituição Federal? Quilombolas e o direito ao território. In SAUER, Sergio e ALMEIDA, Wellington (Org.). Terras e Territórios na Amazônia. Brasília: Editora Universidade de Brasília. 2011, p. 345-360.

SILVA, Liana Amin Lima da; MARÉS DE SOUZA FILHO, Carlos Frederico. Marco temporal como retrocesso dos direitos territoriais originários indígenas e quilombolas. In WOLKMER, Antonio Carlos. MARÉS DE SOUZA FILHO, Carlos Frederico e TARREGA, Maria Cristina Vidotte Blanco. Os direitos territoriais quilombolas além do marco temporal. Goiânia: PUC Goiás. 2016. pp. 55-83.

OIT. Convenção no 169 sobre povos indígenas e tribais e Resolução referente à ação da OIT. Vol. 1. Brasília: OIT, 2011. Disponível em http://portal.iphan.gov.br/uploads/ckfinder/arquivos/Convencao_169_OIT.pdf. Acesso em 04/01/2018. 
TERRA DE DIREITOS. COORDENAÇÃO NACIONAL DE ARTICULAÇÃO DAS COMUNIDADES NEGRAS RURAIS QUILOMBOLAS. Racismo e violência contra quilombolas no Brasil. Curitiba: Terra de Direitos. 2018.

TRECCANI, Girolamo D. Quilombos na América Latina: uma experiência continental. In: PRIOSTE, Fernando Gallardo Vieira; ARAÚJO, Eduardo Fernandes. (Org.). Direito Constitucional Quilombola: Análises sobre a ação direta de inconstitucionalidade 3239. 1ed. Rio de Janeiro: Lumen Juris, 2015, v. 1, p. 59-85.

autor, 2006.

Terras de quilombo: caminhos e entraves do processo de titulação. 1. ed. Belém: 